\title{
A imagética pretérita: perspectivas teóricas sobre a Arqueologia da Imagem
}

\author{
Cibele Elisa Viegas Aldrovandi*
}

\begin{abstract}
ALDROVANDI, C.E.V. A imagética pretérita: perspectivas teóricas sobre a Arqueologia
\end{abstract} da Imagem. Revista do Museu de Arqueologia e Etnologia, São Paulo, 19: 39-61, 2009.

Resumo: $\mathrm{O}$ artigo aborda e discute algumas das principais perspectivas teóricas elaboradas pela Arqueologia da Imagem, que fornecem importantes fundamentos para a análise e a interpretação dos repertórios iconográficos do passado.

Palavras-chave: Arqueologia - Imagem - Iconografia - Semântica Intericonicidade.

\section{Introdução}

s principais perspectivas de análise e interpretação da imagética pretérita pertencem ao campo da chamada Arqueologia da Imagem, desenvolvida principalmente a partir da década de 1970, por arqueólogos franceses e pautada ora pelo formalismo descritivo e pelo estruturalismo, ora pela influência da linguística e da semiótica.

As questões sobre as quais a Arqueologia da Imagem se debruça não envolvem apenas o levantamento e a análise dos elementos iconográficos presentes no repertório dos esquemas formais, tratados a partir da elaboração de um corpus documental. Essa disciplina volta-se essencialmente à análise dos conteúdos temáticos presentes no conjunto imagético e, além disso, busca inseri-los em seu contexto de surgimento e desenvolvimento no intuito de reconstruir e

(*) Pós-doutorado pelo Museu de Arqueologia e Etnologia da Universidade de São Paulo. aldrovan@yahoo.com compreender os aspectos sociais, econômicos, políticos e religiosos que propiciaram sua criação.

Nesse sentido, além da necessidade de evidenciar os conteúdos presentes num determinado repertório iconográfico, a análise arqueológica fornece um embasamento teórico capaz de interpretar a relação entre a produção imagética e o contexto histórico em que esses elementos - formais e temáticos - se desenvolveram. A identificação e interpretação desse tipo de conjunto vestigial, se tratadas a partir dessas perspectivas, permitem a elaboração de um quadro analítico e contextual capaz de fornecer resultados mais objetivos que aqueles encontrados na abordagem puramente estética.

As teorizações elaboradas pela Arqueologia da Imagem fornecem, por sua vez, respostas distintas daquelas elaboradas pela História da Arte. A História da Arte realiza estudos cuja perspectiva está, muitas vezes, voltada à estética e à evolução estilística da obra de arte de períodos e escolas artísticas específicas. Assim, sua preocupação está fundamentalmente centrada no objeto artístico propriamente dito. 
A célebre formulação teórica desenvolvida por Panofsky (1955: 47-87), por exemplo, estabeleceu três níveis distintos a agir na obra de arte. $\mathrm{Na}$ terminologia do estudioso, o primeiro nível é denominado Tema Primário ou Natural e constituído pela descrição pré-iconográfica, a identificação das formas puras do objeto. O segundo, o Tema Secundário ou Convencional, envolve o mundo das imagens, histórias e alegorias e é chamado pelo estudioso de Análise Iconográfica. O terceiro estágio, o Significado Intrínseco ou Conteúdo é constituído pelo mundo dos valores simbólicos e denominado Interpretação Iconológica.

Assim, nesta disciplina, a Iconografia envolve a descrição e classificação das imagens e embora sob certos aspectos possua limitações metodológicas, se adequadamente embasada, fornece elementos importantes para o estabelecimento de datas, origem e, por vezes, autenticidade das peças, assim como fornece as bases necessárias às interpretações ulteriores. Como lembrou o estudioso, esse tratamento que coleta e classifica a evidência, não está capacitado a investigar a gênese e significação da mesma e, por essa razão, constitui somente parte dos elementos que compõem o conteúdo intrínseco de uma obra de arte e que precisam tornar-se explícitos para que a percepção desse conteúdo venha a ser articulada e comunicável.

É importante pontuar que muitas vezes o estudo iconográfico efetuado tradicionalmente pela História da Arte tratou os problemas de interação cultural em termos predominantemente estéticos, o que sempre promoveu abordagens restritivas e uma propensão à apreciação ou depreciação da obra, de acordo com o gosto da época, historicamente determinado. Assim, embasada por uma perspectiva histórica Evolucionista e Difusionista, essa disciplina conferiu à Arte Grega a condição de paradigma, que, contraposto às manifestações artísticas das demais civilizações, procurou relegá-las ao campo do primitivismo (ver Sparkes 1997: 130-155).

\section{O esquema e o tema em Bruneau}

Entre as principais linhas teóricas que abordam a Imagem na Arqueologia francesa destaca-se a teoria imagética de P. Bruneau (1986). Nela, o autor expôs inicialmente a diferença entre imagem e referente. Em suas palavras: "a imagem serve para mostrar o universo das coisas numa relação não idêntica, mas análoga ao referente”. A partir desse postulado surgem dois aspectos inerentes à imagem: o tema, que é relacionado ao referente, e o esquema, relativo à técnica, à ordenação de elementos formais com intuito de produzir uma aparência ilusória do referente. Assim, a imagem compreende a reprodução do referencial ou tema por meio de um esquema (Bruneau 1986: 256-259).

Na concepção de Bruneau (1986: 250, 268), as imagens são definidas como "obras que têm por fim produzir uma representação natural e, especialmente aqui, entre elas, aquelas que têm por objetivo imitar a realidade visível". Ao qualificar a imagem, o autor a inclui na categoria mais ampla de produtos $d a$ técnica, que resulta de uma conduta por meio da qual os meios necessários são fornecidos para sua produção. Como lembrou o estudioso, logo no início de seu artigo:

A imagem não é uma necessidade universal, ela pode não existir, seja ergologicamente, em razão do savoir-faire, seja, mais frequentemente, axiologicamente, em razão do desejo ou direito de produzi-la; mas quando há a imagem, se encontram, obrigatoriamente, os processos próprios à técnica e à representação - o modelo encontra uma validade geral no fato de incluirmos o étnico que tem como efeito particularizar toda produção (Bruneau 1986: 249).

Bruneau criou uma teoria própria da Imagem. $\mathrm{O}$ estudioso discordou dos três níveis estabelecidos pela teoria de Panofksy, descritos acima. Segundo o arqueólogo, "a boa tradição da História da Arte, que se interessa quase que exclusivamente pela estética, considera a obra artística um mero jogo de formas" (Bruneau 1986: 250). Ao arqueólogo da imagem cabe, então, "revelar a identidade dos processos sobre a diversidade infinita de realizações" presentes no conjunto imagético (Bruneau 1986: 252-256) 
Nesse sentido, a construção de um modelo teórico do referencial visual pertinente à Arqueologia tem como ponto de partida aquilo que o estudioso considerou definidor de toda a imagem e de toda obra e sem o qual ela não pode existir, justamente aquilo que, de acordo com ele, o "pan-semioticismo reinante", muitas vezes, negligenciou: sua "tecnicidade". Em seguida, explicou a escolha do termo genérico de referente:

Definida, a grosso modo, como imitante, a imagem é, por sua vez, necessária à coisa imitada. É preciso um termo para designar genericamente aquilo que, na imagem, a técnica usa como trajeto, o que ela tem por fim mostrar o aspecto. A palavra modelo tornou-se uma concepção muito particularizada das ciências humanas e, sobretudo, supõe que a imagem deva representar, sempre, uma realidade previamente sensível, o que não é o caso. Acho mais cômodo o termo referente, mas se fiz aqui esse empréstimo da linguística, não é devido à atual mania de encontrar em tudo a semântica, nem por confusão induzida da arte e da linguagem. É porque, precisamente nesse ponto, a imagem, que serve para mostrar o universo das coisas, está para ele não numa relação idêntica, mas análoga àquela da palavra, que serve ao dizer (Bruneau 1986: 256-257).

Assim, o estudioso verificou que a técnica está duplamente associada ao princípio da imagem, tanto na própria imagem quanto em seu referente, mas que isso não modifica em nada a sua relação com a referência. Bruneau (1986: 257) citou o caso extremo da réplica definida como algo dotado da mesma eficácia ergológica que seu referente, mas que não tem em comum o mesmo status sociológico. Em suas palavras:

A referência não supõe, de modo algum, a realidade da percepção, é por isso que preferi qualificar a imagem como referencial ao invés de imitativa. $\mathrm{O}$ referente muitas vezes não é mais que perceptível e nem efetivamente percebido. O referente pode não ser perceptível pela simples razão de ser destituído de toda realidade sensível, ele surge do que os franceses precisamente chamam a imaginação. A imagem não serve apenas para reproduzir com maior ou menor exatidão os aspectos do sensível de um referente, mas para dar um aspecto sensivel aos referenciais dos quais eles são desprovidos, dentro da realidade não imagética. Porque a imagem é um produto necessariamente técnico em relação a um referente, é preciso distinguir aquilo que nela cabe ao referente, e que chamo de tema; e aquilo que cabe à técnica e que eu chamo de esquema. Em outros termos, o tema não é, cabe entender, o próprio referente, mas sua marca na imagem, que visa mostrar seu aspecto; o esquema é a ordenação dos pontos, linhas, superfícies ou volumes, próprios a produzir ilusoriamente a aparência do referente, resultante do modo como os meios são ordenados final e reciprocamente (Bruneau 1986: 257-258).

As estruturas teóricas propostas para a análise imagética por Panofsky (1955) e Bruneau (1986) são apresentadas na Tabela 1.

De acordo com a teorização de Bruneau (1986: 259), as imagens ou "todas as obras" podem ser classificadas temática ou esquematicamente. Essa distinção entre "esquema e tema é fundamental à análise imagética, pois todo estudo da imagem supõe a escolha de um ou outro ponto de vista, uma vez que tais realidades distintas, mas dialeticamente solidárias, estão mescladas de modo concreto na imagem" (Bruneau (1986: 261). Essa concepção da imagem é essencial, uma vez que se opõe a outras propostas que tendem a confundir a imagem com o referencial - o esquema com o tema. Muitos equívocos interpretativos residem, justamente, na ausência de distinção entre esquema e tema. Isso ocorre, segundo Bruneau (1986: 266, 268), devido ao esquecimento da formalização 
Tabela 1

A Imagem de acordo com Panofsky e Bruneau

\begin{tabular}{|c|c|c|}
\hline & $\begin{array}{l}\text { História da Arte } \\
\text { (Panofsky) }\end{array}$ & \\
\hline $\begin{array}{l}\text { Tema Primário } \\
\text { ou Natural }\end{array}$ & $\begin{array}{l}\text { Tema Secundário } \\
\text { ou Convencional }\end{array}$ & $\begin{array}{l}\text { Significado Intrínseco } \\
\text { ou Conteúdo }\end{array}$ \\
\hline Forma Pura & Mundo das Imagens & $\begin{array}{c}\text { Mundo dos Valores } \\
\text { Simbólicos }\end{array}$ \\
\hline Descrição Pré-Iconográfica & $\begin{array}{c}\text { Análise Iconográfica } \\
\text { Descrição / Classificação }\end{array}$ & $\begin{array}{l}\text { Interpretação Iconológica } \\
\text { Significação simbólica }\end{array}$ \\
\hline & $\begin{array}{l}\text { Arqueologia da Imagem } \\
\text { (Bruneau) }\end{array}$ & \\
\hline ESQUEMA & Mimese e Grama & Referente \\
\hline $\begin{array}{l}\text { Formalização técnica Ordenação } \\
\text { das Unidades Formais Mínimas }\end{array}$ & & Mundo Real ou Imaginário \\
\hline $\begin{array}{c}\text { Análise Iconográfica } \\
\text { Descrição / Classificação }\end{array}$ & & $\begin{array}{l}\text { Análise Interpretativa } \\
\text { Significação Fontes } \\
\text { arqueológicas e textuais }\end{array}$ \\
\hline
\end{tabular}

técnica; da interposição do esquema entre a representação não imagética - o referencial e a imagem, "uma prática costumeira entre os arqueólogos” que conceberam a imagem como uma simples ilustração dos textos ou ainda atribuíram-lhe o papel de transcrição exata e visivel daquilo que representa.

A noção de esquema e sua função mediadora foi também discutida por Sartre (1987: 6465), que o chamou "imagem abreviada, intermediária entre o puro sensível individual e o puro pensamento", a estabelecer uma continuidade entre dois tipos de existência que, em última análise, são inconciliáveis, ele "supera e resolve em seu seio os conflitos entre imagem e pensamento".

A função mais evidente da imagem, na teorização de Bruneau (1986: 269) é a de produzir uma imitação da realidade percebida e, nesse sentido, ela é qualificada pelo pesquisador como mimese. Ocorre que o tema implica não apenas na mimese, mas também em algo que ele denominou o grama - as inscrições que acompanham a imagem. Nas suas palavras:

Tais inscrições nominais, que aparecem na imagética grega, não são mais que a tecnicização facultativa de um componente constitutivo da imagem. Se a imagética recorre, tão frequentemente, à escrita, que tem por fim tecnicizar a linguagem, é de se esperar que uma tenha qualquer coisa a ver com a outra. $\mathrm{Na}$ falta de inscrições inclusas, a imagem quase sempre possui um título constituído por palavras, por vezes, inscrito, posteriormente, sobre uma etiqueta de museu. Em suma, está claro que a imagem não passa de uma única mimese, resultante da representação visual do referente; ela também resulta de sua representação verbalizada, aculturada pela linguagem. Aquilo que, no tema 
participa, não mais do universo percebido, mas do universo dito e, portanto, conhecido. O grama designa todo sinal de implicação verbal. A imagem tem algo comum com a escrita e não nos surpreendemos que ela seja frequentemente epigráfica. A inclusão, constante e necessária, do grama, como componente constitutivo na imagem, não tem nada de misterioso, a imagem carrega simplesmente a impressão daquilo que tem por objetivo tecnicizar (...). Em poucas palavras, a imagem não mostra apenas aquilo que vemos do referente, mas também aquilo que dizemos dele. $\mathrm{O}$ grama importa, portanto, à teoria da imagem e, por ser passível de ser marcado tecnicamente contribui, consequentemente, na sua produção. A imagem não faz ver aquilo que é visível na percepção do referente, mas aquilo que somente é acessivel por meio da linguagem. Para fazer ver o dificilmente visivel, a imagem explora a polisemia de uma palavra; ela mostra aquilo que sugere uma das acepções da palavra utilizada (Bruneau 1986: 272-273).

Steiner (2001: 3-5), por sua vez, observou que a eficácia das estátuas, um tipo específico de imagem, depende de uma construção específica de ligação entre o sujeito e a figuração, um laço que não precisa se apoiar em nenhuma semelhança mimética, mas numa noção de substituição, equivalência ou concordância - uma relação metonímica - de aproximação, contigidade e não similaridade.

Como observou Vernant (1990: 75), a capacidade de o objeto instar, não tanto a aparência física do modelo, mas suas propriedades e valor, permite à imagem assumir um papel em uma dinâmica mais extensa de troca:

Sem se parecer com ele, o equivalente é capaz de apresentar alguém, de tomar seu lugar no jogo de trocas sociais. Ele o faz, não por uma questão de similaridade com o aspecto externo da pessoa (como num retrato), mas por meio de um compartilhamento de valor, uma concordância na questão das qualidades associadas ao prestígio (Vernant 1990: 75).

\section{A Imagem e o poder do discurso imagético}

Outro ponto importante, discutido por Bruneau (1986) e outros estudiosos, é que sempre faltará à Imagem parte do que existe em seu referente, ou, pelo contrário, pode haver algo incluído na imagem que não faz parte de seu referencial original. Assim:

A imagem é incapaz de ser equivalente ao referente, ela reduz o referente ao essencial. (...) A imagem tem por fim reproduzir o aspecto da realidade percebida e, exatamente como a linguagem, é essa, entre todas as suas características, que nós retemos mais espontaneamente: sua capacidade de dizer o mundo, ao invés de sua incapacidade de o dizer, em toda sua propriedade (Bruneau 1986: 268, 278-282).

A função semântica da imagem foi originalmente debatida por C. Dugas (1936: 440) que, antes mesmo de Panofsky (1939), havia elaborado a distinção entre iconografia e iconologia (Dugas 1937). Esse estudioso atribuiu ao conteúdo narrativo um papel preponderante e ao qual a qualidade estética da imagem está subordinada. ${ }^{1}$ Trata-se, portanto, de um

(1) O estudioso analisou um grande conjunto de imagens presentes nos vasos cerâmicos gregos, ao qual atribuiu autonomia e valor formativo próprios, decorrentes de fatores fundamentais da cultura - imagens que até então eram consideradas apenas em seu caráter decorativo ou como ilustrações derivadas da tradição literária. Ele foi provavelmente o primeiro a observar a função ativa das imagens e a re-valorizar seu papel social e educativo - sua missão e ensinamento, entre as diferentes camadas da sociedade grega. Ver, ainda, Lissarrague e Schnapp (1981: 281); e Sarian (1987: 17), sobre a imagem como instrumento da memória. Sobre a história semântica do significado, ver Hoffmann (1988: 144) para quem os objetos não têm significação em si próprios e os símbolos só funcionam em conjunto; e, é claro, Gombrich (1960; 1972) sobre a multiplicidade de significados atribuído a uma imagem, de acordo com o contexto. 
conteúdo fundamentalmente distinto que, condensado em um episódio ou episódios, possui um caráter eminentemente associado à linguagem. Ao evidenciar essa característica narrativa e não apenas estética da imagem, ele revelou seu caráter "comunicativo e capaz de estabelecer modelos culturais na sociedade. Assim, a contemplação destes paradigmas figurativos sugestiona e estimula o indivíduo e, portanto, pode instruí-lo por meio de mensagens dirigidas à coletividade" (Dugas 1936: 440).

Como observou mais tarde Molyneaux (1997a), muitos acadêmicos pensam ser impossível que as imagens existam sem a linguagem. No entanto, compreender uma imagem requer educação e direção da atenção para seus aspectos significativos. Assim, para esse arqueólogo, revelar a vida cultural das imagens significa expor seu poder e influência como afirmação direta das idéias e relações sociais - "mensagens visuais que podem ser tão fortes e distintivas quanto aquelas expressas nos textos" (Molyneaux 1997a: 1).

Essa longa discussão sobre a relação entre a arte, a linguagem e o mundo, discutida também por Bruneau, foi retomada por Molyneaux que observou existir, do ponto de vista analítico, um problema em relação à integração perceptível da imagem:

O uso de imagens naturalísticas implica, supostamente, numa relação direta com a representação do mundo transparente e sem obstáculos interpretativos. As idéias representadas reivindicam uma verdade natural. É por isso que espectadores e leitores se sentem confortáveis diante de imagens de elementos naturais: na arte, tais representações não requerem muita intervenção textual. Uma imagem de um humano pode ser reconhecida fora do domínio relativístico da linguagem, quer alguém fale hindi, inglês, etc. as ações humanas e objetos familiares podem ser detectados sem um guia. A idéia de que representações de elementos naturais fornecem informações simples, diretas e seguras, como a própria natureza, é muito sedutora. Não é de surpreender que o naturalismo (definido, aqui, como uma adesão muito aproximada da natureza ou realidade - como a natureza parece ser) é um instrumento importante de propaganda, tanto política, religiosa ou de divulgação, uma vez que dá crédito às afirmações (Molyneaux 1997a: 2).

Sobre a primazia do naturalismo no esquema imagético, Sartre (1987) ofereceu, uma década antes, um precioso questionamento:

Tendes - dizeis - presentemente, na consciência, uma representação abreviada, muito concreta para ser pensamento, muito indeterminada para ser assimilável às coisas que nos cercam; e denominais essa representação um esquema. Mas porque não seria simplesmente uma imagem? Não confessais, assim, constituindo para essas representações abreviadas uma classe à parte, que reservais o nome de imagem a cópias fiéis e exaustivas das coisas? Mas, talvez, as imagens não sejam nunca cópias de objetos. Talvez não sejam mais do que procedimentos para tornar presentes os objetos de uma certa maneira. Neste caso, o que é que passa a ser o esquema? Não é mais do que uma imagem como as outras, pois o que definirá a imagem será a maneira pela qual ela visa o objeto e não a riqueza dos detalhes por meio dos quais o torna presente (Sartre 1987: 65).

Ressaltamos que se a imagem tem por função o discurso, diferente do texto escrito, que possui maior flexibilidade no que diz respeito à sua extensão, ela precisa ser concisa e direta, uma vez que está circunscrita ao espaço formal da obra. Nesse sentido, esta propriedade da imagem, aqui chamada sintética e seu próprio caráter visual propiciam uma difusão mais ampla e, portanto, também mais direta, ágil e persuasiva do discurso que engendra. Como observou Shapiro:

Artistas pictóricos vêem o mundo de modo distinto dos poetas, que recorrem 
às palavras. Nós não podemos mais reconstruir a experiência de ouvir uma performance de Homero ou Stesícoros, ou assistir a uma peça de Ésquilo, como os atenienses do século $\mathrm{V}$ o fizeram. Ao olhar o vaso grego, no entanto, podemos ter certeza de que estamos vendo o mesmo objeto que o comprador original e seus amigos viram. Nesse sentido, as artes visuais dos gregos, nos falam mais imediatamente e diretamente do que a poesia poderia. No entanto, existe aí, também, um perigo, pois nós estamos olhando os objetos com olhos distintos e pressupostos culturais, estéticos e perceptivos diferentes (Shapiro 1994: 10).

Como observou Bérard (1974, p. 46-47), em relação à qualidade semântica dos vasos, não se trata de negar o valor artístico dos vasos no plano da História da Arte, mas de verificar uma outra importante função da imagem: "a imagética retém o tema - a história narrada que pretende transmitir, assim, enquanto a história faz os tipos evoluírem, o estilo de cada época os modifica".

Não é nenhuma novidade que o acesso aos textos escritos na Antiguidade era muito mais reduzido e limitado às elites do que as imagens. A linguagem escrita requer um conhecimento anterior, bem mais específico e vagaroso, para compreensão efetiva do discurso. A leitura da imagem, por sua vez, também exige um conhecimento prévio, mas este se dá de modo distinto daquele que é necessário à leitura do texto. Como recordou Sparkes (1997: 132), nas sociedades iletradas ou parcialmente letradas, as imagens têm um papel importante. Entre os gregos, observou o estudioso, o grande impulso verificado na oratória e nas imagens indica que o ouvir e o olhar eram mais influentes na vida cotidiana do que o ler. Na atualidade, isso se confirma quando observamos que a população tem acesso muito mais facilitado às formas de expressão visual que literárias, ou constatamos sua utilização indiscriminada na mídia, por meio de agentes do discurso verbal invariavelmente congregados ao discurso visual. A influência da imagem nos meios de comunica- ção de massa foi tema exaustivamente tratado por estudiosos da semiótica.

Ao mesmo tempo, esta função sintética foi interpretada, por Molyneaux, como a inércia da imagem:

O fortalecimento de idéias em algumas imagens é muito poderoso. Representações históricas ou religiosas de indivíduos, episódios ou eventos importantes, fornecem um resumo intenso, denso e engajado de eras inteiras e situações bastante complexas. Cada imagem captura literal ou figurativamente, um momento congelado no tempo, mas que pode eventualmente durar uma eternidade. Trata-se de um conceito estranho: a compressão de tempo e espaço em uma única imagem. O problema é que a imagem supera o tempo e a academia, ao capturar a essência imaginada de um evento de forma facilmente lembrada, replicada e transportada. Se for um evento humano, é ainda mais resistente à mudança. Nós tendemos a descartar ferramentas e tecnologias que não são mais necessárias, mas preservamos a arte, como símbolos que ainda são válidos à experiência humana. Imagens e outras representações visuais possuem, portanto, uma inércia tremenda, um poder de permanência, que pode persistir por muito tempo, após as idéias por trás delas saírem de moda. Essa persistência e, frequentemente, anacronismo, pode ser observado na arte ao longo da história (Molyneaux 1997a: 6).

A continuidade ou capacidade de permanência da imagem foi abordada por Shanks (1997) a partir do conceito de retórica do discurso imagético engendrado pelas fotografias, geralmente consideradas um poderoso instrumento retórico para estabelecer objetividade.

Elementos de retórica incluem técnicas de persuasão, estilos de apresentação, formas de argumentação e arquivos para referência e apoio. Assim, 
em Arqueologia, uma afirmação ou uma imagem do passado arqueológico, não é forte e boa porque é verdadeira ou objetiva, mas porque congrega e faz sentido, porque, quando interrogada, é considerada objetiva. Em que casos então uma afirmação ou imagem possui força, se não na objetividade? Pode não haver resposta, ou elas podem ser muitas. Uma imagem objetiva, uma verdadeira representação da realidade, é aquela conectada a algo mais sólido que ela mesma, de forma que, se for considerada não-representativa, tudo aquilo a que ela está conectada fica ameaçado de ruir. Retórica é a arte e a ciência de fazer tais conexões e persuadir as pessoas de sua força. Uma foto possui uma multiplicidade de conexões possíveis que fazem parte da heterogeneidade do trabalho fotográfico. A objetividade de um registro arqueológico, sua força, é uma realização retórica, mas nem por isso é real.

(Shanks 1997: 81-82).

Shanks também afirmou que aquilo que consideramos realidade objetiva é uma construção retórica, uma vez que a objetividade e a verdade não se sustentam em si mesmas. Elas devem ser argumentadas e, assim, a força da objetividade advém, em parte, da retórica. Isto é, para fazer sentido, uma imagem precisa ter conexões e contextos estabelecidos que operem dentro e além da imagem, de forma que o espectador possa reconhecer ali relações sociais específicas. Isso pode ocorrer tanto com seu tema quanto com a composição, o esquema.

Muitos estudiosos, nas décadas passadas, se voltaram para a análise da produção artística e dos artistas, em detrimento da influência do contexto na produção das imagens e da obra dos artistas, de acordo com as diferentes realidades regionais. Bandinelli (1961: 43-44) foi um dos pioneiros nessa abordagem, ao observar que o repertório imagético é adaptado a um discurso figurativo referente à realidade local e que a imagem possui uma função educativa e, portanto, social.
A análise estilística tradicional não favorece a aproximação da situação de produção das imagens, isto é, do contexto material e social em que o artista trabalhou, e nem mesmo dos indivíduos e da sociedade que os produziu. Estilo, como lembrou Molyneaux (1997b: 109), presume diferenças individuais e isso encoraja os analistas a generalizar. A alternativa, segundo o estudioso, é olhar para as referidas imagens como:

Ambientes materiais que contêm várias áreas de atividade material e ideológica, locais onde indivíduos, imbuídos das atitudes de seu tempo, marcaram as superfícies das paredes. Pois, apesar da noção abrangente de obras de arte, como elemento raro e valioso, imagens são, geral e simplesmente, áreas contendo informação de um tipo (e densidade) diferente das paredes ou outras superfícies ao seu redor. Cada imagem registra traços da situação da produção artística, que inclui aspectos do estado físico e intelectual do artista, traduzido por meio de um pincel, cinzel ou outro instrumento, em feições materiais na superfície da imagem. Imagens terão, portanto, evidências visíveis das atitudes implícitas e explícitas do artista, ou da posição que eles tomam, diante do seu tema (Molyneaux 1997b: 109).

As representações surgem e permanecem inseridas em circunstâncias temporais específicas, condicionadas pelas pressões sociais, econômicas e políticas de um determinado momento. A sucessão do poder por novos grupos étnicos, sociais, religiosos estabelece demandas precisas que, por sua vez, condicionam o desenvolvimento do programa iconográfico. Nesse sentido, as observações de Molyneaux são bastante pertinentes:

Imagens são particularmente eficientes para reforçar poder e ideologia. A visibilidade das imagens como formas materiais emprestam força a qualquer mensagem que elas expressem. Esse 
estímulo perceptivo descreve a alteração de algum aspecto do ambiente percebido, de modo a ampliar a probabilidade de que ele seja digno da atenção de uma diversidade de espectadores. A manipulação da atenção para chamar a atenção pode ser intencional. O esforço pelo efeito, frequentemente, responde ao declínio de um estilo ou moda nas coisas culturais. O que sugere que a análise do conteúdo possui um papel potencialmente significante no estudo das imagens, no estudo das variações da forma do significado, uma vez que este é afetado pela variação do estímulo ideológico. Estímulo perceptivo também é um atributo essencial, pois sugere não apenas que as imagens têm existência além da linguagem textual, mas que imagens e artistas não podem estar totalmente circunscritos pelo relativismo cultural, social ou perceptivo. O uso de estímulos visuais intensos ajuda a gerar o poder de persuasão utilizado tão eficazmente hoje na publicidade. É necessário examinar tanto os atributos materiais como sociais das imagens (Molyneaux 1997a: 4-5).

A arte, conclui Molyneaux (1997a: 5-6), é uma fonte lógica para o estudo do poder em uma sociedade, uma vez que é essencial ao aparato que reforça a ideologia para as massas. Assim, para examinar os efeitos do estímulo metafórico e perceptivo, que esse estudioso considerou a essência do poder das imagens, é necessário estudá-las em seu contexto de produção.

Artistas e espectadores se conectam a um discurso já em progresso, e nós podemos conhecer melhor as forças sociais que geram as imagens dentro desse discurso a partir das variações formais nas imagens individuais que, como elementos de informação, são manipulados como parte do estímulo perceptivo e metafórico (Molyneaux 1997a: 5-6).
Esse arqueólogo lembrou, ainda, que é possível identificar a posição do artista sem, necessariamente, conhecer o seu significado preciso em pelo menos um aspecto da arte: a forma e distribuição das figuras humanas e a representação de cenas e eventos sociais. Assim:

Representações de paisagens sociais são bastante sensíveis às situações ideológicas contemporâneas e, é claro, suscetíveis a uma variedade de leituras modernas, porque elas estão parcialmente preocupadas com o reconhecimento e apresentação do status social dos indivíduos. As variações e diferenças no tamanho relativo e na orientação de figuras individuais em uma cena, que a análise estilística torna clara, são nossas principais preocupações. Elas podem ser resultado de variações simples do esboço. Mas, elas também podem expressar uma atitude consciente ou inconsciente do artista diante do tema. Ao tomar o tamanho relativo como forma de representar significação, uma técnica comum em pinturas sem perspectiva, o artista provavelmente pintará a figura mais importante, ou as cenas, maior que as demais. Mesmo que nós desconheçamos mais ou menos os temas, significados, ou detalhes iconográficos da pintura, nós podemos observar a imagem e ao menos compreender a organização da significação na mesma. Se, nós observamos que tal padrão recorre em uma quantidade de pinturas de diferentes artistas, podemos especular que ela reflete uma atitude social mais predominante. (...) Dessa posição, nós podemos ser capazes de ver o dinamismo escondido nas imagens, que na superfície parece tão controlado e consistente - diferenças formais surgem de variações situacionais, refletem a veracidade da obra representacional do artista influenciada por circunstâncias psicológicas e práticas mutáveis, no local de trabalho (Molyneaux 1997b: 111-112). 
Se o a rtesão é tanto fator causal quanto resultado da evolução artística, social e religiosa de sua época e se cada contexto propicia e resulta da interação desses diferentes fatores, eles não podem ser desconsiderados numa análise efetiva. Como lembrou Hoffmann:

A mera idéia, de que as imagens individuais nos vasos geométricos são imbuídas de significados diretos e monosemânticos que o artista tinha em mente, é baseada em um equívoco profundo do que são símbolos e de como eles funcionam, e na crença errônea de que a expressão simbólica se opõe, de alguma forma, à expressão direta ou representacional. O pensamento simbólico se torna coerente, e seu estudo interessante, quando os símbolos empregados são examinados em conjuntos e quando a relação entre símbolos e conjuntos de símbolos é estudada dentro do contexto cultural como um todo (Hoffmann 1985/6: 62).

Por outro lado, uma observação essencial feita por J. P. Vernant refere-se à incerteza que envolve decifrar uma imagem. Nas suas palavras:

Nenhum sistema figurativo é a simples ilustração do discurso - oral ou escrito -, nem a reprodução fotográfica do real. A imagética é uma construção, não um decalque; é uma obra cultural, a criação de uma linguagem que como todas as outras línguas comporta um elemento essencialmente arbitrário. A palheta de formas figuradas, que cada civilização elabora e organiza, a seu modo e estilo, sobre uma determinada superfície, surge como um produto filtrado, uma codificação do real a partir das modalidades que lhe são próprias. Tal arbitrariedade social é que explica a dificuldade em decifrar as imagens e justifica o projeto de buscar, por meio delas, os traços específicos de uma cultura (Vernant 1984: 5).

Nesse sentido, Bérard e Durand lembraram que:
A leitura de uma imagem exige do observador moderno uma ginástica intelectual que não é complicada, mas que precisa de um treino progressivo; é sempre preciso considerar que nós estamos distanciados das condições que existiram durante sua elaboração. Nem os textos, literários ou epigráficos, nem as escavações em campo, nem o conjunto imagético permitem reconstituir totalmente a conjuntura histórica que torna compreensível o documento em questão (...). É na análise das regras que estruturam a combinação que o sentido da cena aparece progressivamente. $\mathrm{O}$ documento deve ser inserido em uma série de imagens e a estas devem ser comparadas às diferentes combinações que regem a nova imagem. Uma imagem isolada tem grandes chances de permanecer muda; uma rede de imagens, pelo contrário, quer pelas semelhanças ou diferenças que apresentam suas combinações, começam a fornecer as significações. É ai que reside a maior dificuldade da interpretação: para poder medir os desvios diferenciais que distinguem as imagens e, assim, estabelecer as regras compositivas obedecidas pelos artesãos, aquele que deseja as decifrar deve ter, constantemente, em mente o conjunto imagético; essa ginástica mnemônica se torna o melhor meio de se abordar as antigas condições de criação (Bérard e Durand 1984: 19, 21).

Algumas vezes, um repertório artístico intervém sob a forma de um programa iconográfico preciso e doutrinário, como no caso da arte religiosa. Como observou $\mathrm{T}$. Champion:

As representações do passado, que compreendem a pintura e a escultura, são categorias complexas. Elas promovem indagações a respeito do poder de transmitir uma mensagem; tais imagens podem permear a sociedade e se tornarem duradouras se forem continuamente projetadas, repetidas e renovadas, se tiverem a capacida- 
de de exercer uma influência e deixar um legado para além do tempo e espaço, ou da esfera cultural restrita em que foram originalmente criadas (...). O foco primordial está na produção e disseminação das imagens, embora isso não possa estar dissociado de uma consideração sobre o contexto político e ideológico (Champion 1997: 213).

Como havia notado Hoffman anteriormente em relação ao papel da imagética:

Primeiro, e antes de mais nada, existe a questão da visualização em geral. A religião não é uma simples questão de ver e acreditar. Ela é mais como uma enciclopédia, na qual certas visões de mundo são validadas e preservadas de geração em geração. O mundo invisível do mito é compartilhado por meio de imagens, especialmente entre as pessoas que não podem ler. A função da imagem é materializar, equilibrar e estabelecer a ideologia no tempo e no espaço (Hoffmann 1988: 153).

Nesse sentido, Steiner, que pesquisou as esculturas gregas arcaicas e clássicas, propôs que:

Como artefatos-chave na paisagem cultural, as imagens também se desenvolvem junto das mudanças e desenvolvimentos no tempo e espaço. Colocar as imagens nesse contexto mais amplo nos permite recuperar muitas atitudes e crenças acerca das mesmas, e algumas das respostas que elas teriam suscitado. Nenhuma escultura foi erigida sem uma função a realizar. Seja com intenção apotropaica, talismânica, admonitória, consoladora, votiva ou comemorativa, estátuas eram, primeiramente e acima de tudo, vistas, não como objetos representacionais ou estáticos (embora sua beleza e qualidade fossem geralmente cruciais ao desempenho de seu papel), mas como agentes performativos e eficazes, capazes de interagir em uma variedade de maneiras com aqueles que as patrocinaram e veneraram (Steiner 2001: xii).
Esses eram elementos conhecidos e, certamente, empregados pelos patrocinadores da arte e das imagens, na difusão dos ideais contemporâneos vigentes, quer políticos ou religiosos.

\section{O texto e a imagem, a imagem e o texto}

Uma outra questão importante e amplamente discutida pelos estudiosos da Imagem, diz respeito à confrontação entre as fontes textuais e visuais da Antiguidade.

Ao longo do século XIX, as pesquisas iconográficas foram desenvolvidas sob uma perspectiva que tendeu associar ou submeter a imagem ao texto. Baseada na abordagem filológico-histórica, na qual a Arqueologia era considerada subordinada à Filologia, a imagem era concebida como mera ilustração das fontes escritas. Se os estudiosos não encontrassem respostas nas imagens, procuravam-nas nos textos e, se estes não as fornecessem, imaginavam uma fonte literária perdida.

Nessa época, os arqueólogos imputavam aos atributos um papel determinante nas imagens. Mas, o avanço das pesquisas revelou que não havia uma relação direta entre imagem e texto e que os atributos não eram determinantes, pois existiam outros fatores envolvidos na interpretação da imagem, que até então, tinham sido ignorados.

$\mathrm{O}$ valor absoluto do atributo que recebeu primazia entre os eruditos foi discutido por Metzger (1985: 173-179), que resumiu a questão ao postulado: "a imagem, para aquele que a produz e para aquele que a recebe, possui necessariamente um sentido preciso e inequívoco". Por vezes, tal sentido escapa à perspicácia do erudito moderno e, nesse caso, o tema permanece desconhecido. Para esse estudioso, diante de um jogo de imagens em que a composição parece clara, mas a sintaxe pouco evidente, o arqueólogo encontra-se na situação do linguista, procurando decifrar uma língua morta transcrita em caracteres conhecidos ou, ao encontrar uma linguagem iconográfica incerta, na situação do viajante, cujos interlocutores falam uma língua total- 
mente desconhecida. O arqueólogo dos registros figurativos, que não dispõe de um código de tradução infalível, procede a fazer aproximações e, por vezes, até regredir. Assim, um documento isolado pode não ser compreendido, mas o surgimento de outro pode ampliar a certeza. No entanto, é sempre preciso atentar para a ambiguidade de um atributo e, portanto, na visão desse estudioso, é necessário reduzir o número de seus significados e reagir com prudência diante da multiplicidade de significantes.

Outro problema interpretativo que existiu nesse período foi a suposta igualdade entre documentos imagéticos mais antigos e mais recentes, como se estes constituíssem uma mera genealogia iconográfica. Sob a influência do Evolucionismo, a Antropologia, a História das Religiões e a Arqueologia Clássica demoraram a perceber que existem marcos importantes na constituição da imagem e que, muitas vezes, não é possível instituir uma filiação direta.

Houve, ao mesmo tempo, um exagero na atribuição da influência da Grande Arte nas artes menores. Toda vez que uma pintura era estudada em vaso cerâmico, imaginava-se um original escultórico ou uma pintura que teria servido de modelo, mas que se perdera no tempo. No entanto, as pesquisas mais recentes verificaram que não se podem comparar de forma direta produtos provenientes de produções intelectuais distintas, muitas vezes produzidos e dirigidos a diferentes camadas da sociedade. Clermont-Ganneau (1878; 1880) foi o primeiro a discutir essas questões e chamar a atenção para a proeminência da imagem ao cunhar o termo mitologia iconográfica e iconológica. Mais tarde, o próprio Dugas (1937) redigiu um artigo em que contrapôs a tradição literária à gráfica, no qual abordou a imagem como forma de expressão particular e independente da produção textual, cada qual com modos de produção diferenciados.

$O$ positivismo engendrado pela iconografia descritiva durante o século XX e que deu ênfase ao formalismo de inspiração estruturalista foi, mais tarde, confrontado a abordagens de cunho antropológico e semiológico. $\mathrm{O}$ componente social também passou a ser considerado fundamental para análise da imagética grega. Assim, os estudiosos passaram a se interessar pela descoberta dos níveis semânticos por trás do fenômeno descritivo. ${ }^{2}$

Nas palavras de Lissarrague e Schnapp:

As imagens não são mera decoração, arbitrária ou gratuita; elas não podem ser um produto cultural insignificante (...). As imagens não são o complemento figurado de uma realidade social que os textos, mais ou menos, nos revelam. Não há imagem que seja, em si mesma, um documento sociológico; identificar um artesão, um escravo, um meteco, por exemplo, não basta. O que é apresentado são as várias categorias: velhos, mulheres, cavaleiros, hoplitas, por exemplo, que na imagem são agentes narrativos, não dados estatísticos. Para evidenciar as regras funcionais da imagem, único passo possível, devemos utilizar a obra dos linguistas e dos teóricos da arte, para tentar construir uma semântica da imagem visual. (...) Tal análise do sistema icônico conduz ao reconhecimento do trabalho do imaginário social, o modo como os gregos se viam. Fornecer acesso às representações mentais não é o menor paradoxo dessa pesquisa (Lissarrague e Schnapp 1981: 281).

Nesse sentido, como observou Gombrich (1960: 388-389), a arte "não é apenas um instrumento de informação, mas também um meio de expressão". Entre a língua falada e figurada, sempre haverá essa diferença, uma recorrerá aos signos arbitrários, a outra às formas que, "por serem simbólicas ou convencionais não têm menos fundamento na realidade, mesmo que já filtradas por representações mentais".

(2) A partir da década de 80 é que os estudos iconográficos tomam novo fôlego. Para uma historiografia ver Lissarrague e Schnapp (1981); Hoffman (1985/6: 61-66) e a chamada iconologia interpretativa; e também Sarian (1987: 15-48). 
A antiga suposição de que as fontes escritas teriam invariavelmente originado o repertório imagético não se confirmou durante as análises da iconografia grega, e a existência de uma tradição figurativa independente da tradição literária, consequentemente, foi atestada. Embora em alguns casos a literatura tenha servido de ponto de partida ou fio condutor na produção figurativa, tal premissa revelou-se falaciosa, pois negligenciava toda a influência que não fosse literária.

A pesquisa realizada por Moret (1975), por exemplo, conduziu a essas constatações. Quanto mais se escrutinaram os documentos, menos transpareceu a idéia geralmente aceita de uma primazia absoluta do texto como fonte de inspiração da imagem. Ao demonstrar que os pintores trabalharam a partir de fórmulas preestabelecidas, o estudioso pôde verificar as proporções da suposta influência literária e restituir a parte de criação que coube à tradição figurativa. $\mathrm{O}$ fato de elementos intercambiáveis condicionarem a formação das representações lendárias modificou sensivelmente a idéia que se fazia da mitologia figurada. Seu estudo mostrou-se extremamente interessante ao verificar que certos procedimentos de composição ali analisados revelaram um modo particular de transmissão e evolução dos mitos em uma zona periférica do mundo grego.

No caso da Grécia, cabe lembrar, essa dissociação e autonomia entre imagem e texto esteve possivelmente associada ao fato de a religião grega não possuir uma doutrina canônica rígida. Embora o panteão grego seja o mesmo, a fragmentação política permitiu a cada região, seja na Grécia ou em suas colônias, apresentar variações na natureza das divindades e lhes imprimir características regionais próprias e, por vezes, distintas. Tal especificidade acabou por se refletir na arte grega, na qual mestres e artesãos, favorecidos por essa ausência dogmática, puderam exercer uma liberdade criativa e expressiva única, que apenas se tornaram cânones formais durante o período Clássico e Helenístico. No entanto, é preciso lembrar que se tratava de cânones artísticos, de caráter estético e não-religioso. ${ }^{3}$

O conhecimento dos textos é indispensável, mas como demonstrou Panofsky (1939: 25 27), não podemos aplicar qualquer texto a qualquer imagem. $\mathrm{O}$ fato de um determinado texto fornecer a melhor chave para interpretação de uma cena não implica necessariamente que o pintor o tenha utilizado como inspiração para compor sua cena. Além disso, a comparação entre imagens e textos serve para evidenciar a independência das duas tradições, que se medem, nesse caso, em termos de desvios diferenciais.

Como observou Bruneau (1986: 266, 174), o problema de considerar a imagem como a ilustração dos textos decorria da crença tácita na transparência da imagem, como se ela fosse a cópia fiel das coisas que mostra e a transcrição visível exata da representação mental que ela informava com toda segurança. $\mathrm{O}$ estudioso lembrou que nas civilizações sem texto, o grama da imagem é esquecido, mas a Arqueologia, desenvolvida a partir das civilizações com texto, o privilegia a tal ponto que a imagem não passa de uma ilustração, um reflexo, um substituto do texto e, assim, deduz-se que a imagem procede apenas da linguagem:

A imagem pode proceder tão bem mimeticamente, de um perceptível que não pode ser concebido, de um visto que é sempre dizivel, e, gramaticamente, de um conhecido que podemos tornar perceptível, de um dito visualizável, porque imageável, portanto, imagético.

(3) Nesse sentido, Shapiro (1994: 7) observou que a imagética do mito grego nunca foi constituída por um dogma religioso como foi a iconografia cristã e, por isso pôde ter muito mais liberdade, tanto na escolha do tema como na forma de representação: "se os gregos escolheram se cercar de imagens, foi mais por uma razão estética que religiosa”. Como também verificou Meneses (1967: 35), ao discutir o uso da perspectiva na imagética Clássica, não havia na Grécia, como em outra civilizações, entraves a essa busca, pois "o individualismo da vida religiosa grega evitou a formação de cristalizações formais e não pôs obstáculos à especulação que fazia da natureza, para um grego, e sob todos os seus aspectos, fundamentalmente e antes de mais nada, um objeto para um exercício da razão humana”. 
Ela imita tão bem o visto, que visualiza o dito. Se a técnica for colocada de lado, as representações visuais e verbalizadas são, na realidade concreta, muito intimamente mescladas, para que uma preceda ou domine a outra. Por outro lado e, sobretudo do ponto de vista que nos importa, a técnica, sem a qual não haverá imagem, pode indiferentemente servir à mimese e ao grama. $\mathrm{O}$ esquema não distingue imagens realistas e imaginárias (Bruneau 1986: 175).

Em relação à análise imagética e textual, Steiner propôs uma reconciliação:

Os textos são necessários porque apenas as fontes literárias contemporâneas são capazes de nos fazer entender como os gregos conceituavam a escultura; e, as imagens são necessárias aos textos porque, sem elas, não podemos compreender o papel da escultura como uma classe de objetos. E, em certos casos, como um instrumento literário utilizado na poesia, retórica e filosofia. A escultura é uma tipologia única, a sua tridimencionalidade, a ocupação do mesmo espaço real que o espectador habita, e seu lugar central nas práticas sociais, políticas, religiosas e mágicas, imbuem-na de facetas únicas. Os textos contemporâneos fornecem informações a respeito das práticas rituais e tradições anedóticas a respeito das imagens antigas. Textos posteriores possuem mentalidades e programas diferentes. Por isso, existe a necessidade de uma abordagem mais ampla, em que o todo gere uma narrativa mais coesa e completa do papel das estátuas na vida cotidiana, nos pensamentos e práticas dos antigos espectadores (Steiner 2001: xiv).

A análise de Shapiro (1994: 6), da mesma forma, demonstrou que o repertório do pintor possuía um fluxo constante que era em parte uma resposta ao estímulo externo, como as novas obras literárias ou, mais tarde, representações teatrais, mas que ao mesmo tempo era um reflexo da dinâmica interna dessa forma de arte.

Outro estudioso a fornecer uma importante teorização sobre a linguagem imagética foi Snodgrass (1982: 5; 1987: 11, 13) que também trabalhou com a linguagem narrativa das imagens. O autor identificou quatro tipos principais de métodos narrativos - sinótico, monocênico, cíclico e contínuo - utilizados no processo de construção da imagética grega. Esses modos de narração também são encontrados nos repertórios imagéticos das demais sociedades antigas.

O método sinótico é uma convenção por meio da qual se representa, em um campo delimitado, uma narrativa de episódios que são sucessivos nas versões orais ou literárias; porém, (condição muito importante) sem que uma figura individual apareça duas vezes (o protagonista é apresentado uma única vez na cena). Ele envolve a combinação de diferentes momentos ou episódios de uma história em uma única representação, na qual não existe unidade temporal ou mesmo espacial. A ação é articulada em diferentes momentos e lugares, exprimindo relações de espaço e tempo com grande economia de meios, mas dotada de riqueza semântica, capaz de garantir articulação e compreensão. A imagem corresponde a um momento impossível que não poderia ser fotografado.

O método monocênico, por sua vez, é a representação de um episódio isolado e preserva a unidade de tempo e espaço, no momento culminante da ação, também chamado fotográfico.

Em seguida, no método cíclico, a narração dos episódios se dá por meio de quadros sucessivos, separados fisicamente, com a repetição da figura do protagonista e outros personagens em cada cena.

Finalmente, o método contínuo é uma variante do cíclico, no qual não há limites físicos entre os episódios individuais. Ele não foi uma invenção grega, mas do Oriente Próximo e reaparece, por exemplo, na Arte Romana (ver Moret 1975: 299). 


\section{4. $\mathrm{O}$ tipo de suporte e a linguagem imagética}

Embora existam estudos que concebem a análise imagética como um campo de pesquisa independente, não necessariamente associado ao seu suporte, cabe notar que os vasos cerâmicos gregos são objetos arqueológicos portadores de imagens (ver Lissarrague e Schnapp 1981: 275; e Sarian 1987: 15) e que esse repertório se expressou e evoluiu de acordo com o suporte que lhe serviu de apoio. Assim, o tipo de suporte em que um conjunto imagético foi criado também merece atenção e sua análise deve considerar a especificidade de cada tipo de objeto, edifício, etc.

Como observou Bérard (1974: 47, 51, 163), diferentes da obra de arte que encerra uma qualidade estética de criação original, os vasos cerâmicos na Grécia - objeto principal das pesquisas imagéticas francesas - possuem uma qualidade primária de cunho discursivo - seja essa de temática mítico-religiosa ou secular. Os ceramistas, por sua vez, tinham um repertório relativamente limitado de unidades formais minimas, para transcrever temas muito variados. Essa conceituação, mais tarde, foi explicitada da seguinte maneira:

Os elementos constitutivos da imagem são, portanto, estáveis e constantes. É este que chamamos o repertório de unidades formais minimas; este repertório é comum a todos os artesãos e conhecido de todos os clientes. Por outro lado, as combinações variam. É no nível combinatório que se obtém o sentido da imagem (...). As unidades figurativas combinam-se, entre si, de modo quase mecânico, a fim de produzir um sentido livre, o mais possível, de ambiguidade. Nessa perspectiva, a relação de referência com a realidade importa menos que a relação de significação. $\mathrm{O}$ imagista constrói sua imagem por aproximação à imagética e não em obediência fiel às leis da reprodução, quase fotográfica, da vida cotidiana (Bérard e Durand 1984: 23).
Assim, enquanto os artistas buscavam escapar dessa limitação esquemática do sistema imagético, renunciando ao procedimento icônico e recorrendo aos comentários de tipo linguístico, os melhores artesãos eram aqueles que conseguiam, como explica Bérard, bricolar as unidades formais mínimas num esquema, por meio de combinações variadas, até manifestar claramente a intenção de comunicação, que deveria ser o menos ambígua possível. A expressão que, nesse sentido, é mais próxima da linguagem do que da arte, é obtida a partir de um conhecimento anterior do repertório das unidades formais utilizadas pelos artesãos para compor suas imagens.

Bérard (1974: 47, 165) observou que a "estabilidade formal do esquema fixado pela tradição permanece e, mesmo que novas situações surjam, os elementos figurativos constitutivos provêm de um patrimônio comum". Se o artesão suspeitava da ambiguidade de uma interpretação, ele a remediava por meio do acréscimo de um signo adequado e conhecido, que chamamos aqui recognitivo, ou seja, que permitia a leitura correta da imagem. $O$ único meio de se chegar a esse objetivo é utilizar as unidades figurativas estáveis combinadas sistematicamente.

Assim, para Berárd (1985: 164-166, 168 169), a principal chave de decifração, tanto no nível de criação das imagens quanto no de sua leitura, reside na inclusão de certo número de unidades formais que permitam ao leitor operar a passagem do esquema ao tema. Os detalhes das cenas eram, segundo o pesquisador, os detentores do sentido da imagem. $\mathrm{O}$ funcionamento das unidades formais mínimas depende do conhecimento prévio do espectador - a população precisa conhecê-los para identificá-los e, assim, compreendê-los, para que possa então reconhecer a cena. Tais unidades, que incluem os personagens, seus atributos e gestos, depois de um longo tempo, se tornavam parte da bagagem de toda a coletividade. Um enorme conjunto de imagens difundiu-se por todas as camadas sociais e a leitura dessas cenas era feita por qualquer uma delas, mesmo sem requinte erudito. 
Em alguns casos, as unidades não ocorrem em número suficiente para permitir que o tema surja claramente a partir do esquema, ou seja, de forma que a imagem possa ser identificada. As dificuldades provêm precisamente, acredita o estudioso, das tendências erradas adotadas pelos arqueólogos que procuram descrever apenas aquilo que está relacionado às imagens - o esquema -, ao passo que são as unidades formais mínimas que criam os elementos diferenciais geradores dos temas - o sentido. Assim, diferente do sistema linguístico, o sistema iconográfico é fechado porque a imensa maioria das unidades formais mínimas, suscetíveis de combinação, não é arbitrária.

A mesma idéia foi compartilhada por Moret (1975: 4), outro estudioso da Imagem, pois "longe de ter um papel passivo o espectador também constrói a cena que tem diante dos olhos em função dos esquemas preexistentes". O conhecimento que ele tem do mito ou que, em alguns casos precisamente, não tem, dita o seu comportamento diante da imagem: ele projeta sobre a mesma aquilo que já sabe, aquilo que espera encontrar. Nos vasos, o observador não saberá o sentido se não conhecer antes o tema e entender de mitologia grega para decifrar o conteúdo das representações. Mesmo o especialista, diante de uma cena que não é descrita nos textos ou cujas fontes não fornecem um testemunho correspondente, será incapaz de encontrar a chave para a interpretação. Para esse arqueólogo:

O elemento visual é, sem dúvida, primordial, mas é apenas um modo de representação. A imagem tem uma semântica de segundo grau. A leitura é sempre referencial, ou seja, ela remete a um dado que não está inteiramente contido na imagem. O termo leitura é, nesse sentido, mais que uma metáfora na medida em que há uma assimetria entre a leitura e a visão (Moret 1975: 299).

Tal fenômeno foi explicitado por Barthes, que observou:

A imagem se torna escrita no instante em que se torna significativa, ao ser atravessada pelo olhar que se carrega de sentido é aniquilada enquanto imagem pelo olhar-leitor. No significante mítico, a forma é vazia, mas presente, o sentido está ausente e, portanto, pleno. A imagem tem, de alguma maneira, o papel de catalisador, despertando no espírito mecanismos reminiscentes e associativos que fazem com que o espectador conecte a cena que tem diante dos olhos a um contexto familiar (Barthes 1970: 195, 209).

Nesse sentido, Sarian observou que:

Na narração e na transmissão de mitos e ritos, o pintor imprime nas imagens uma versão que corresponde às crenças coletivas, aquelas que se cristalizaram na aceitação popular. $\mathrm{O}$ universo imagético tinha, por isto, um grande alcance: inspirado na tradição e voltado para o grande público estava na confluência dessas direções, o meio propulsor e o meio receptor. A tal ponto que para o grego antigo, identificar imagem mítica ou religiosa era reconhecer o seu próprio patrimônio espiritual (Sarian 1987: 48).

\section{A semântica imagética: continuidade e inovação na imagem}

O modo como o repertório imagético evolui, seja na forma ou significado, sincrônica ou diacronicamente, é algo extremamente pertinente e abordado de modo recorrente pelos estudiosos da Imagem. Assim, a verificação dos elementos intrínsecos ou extrínsecos que condicionam a estabilidade ou as modificações esquemáticas e temáticas e que afetam diretamente a semântica imagética merecem algumas considerações.

Como observou Focillon, pode-se conceber a iconografia de muitos modos:

Seja como a variação das formas sobre um mesmo sentido, seja como a variação dos sentidos sobre a mesma 
forma. Um método ou outro traz, igualmente, à luz a independência respectiva dos dois termos. Tanto é que a forma exerce uma espécie de magnetismo sobre os diferentes sentidos, ou mais que isso, ela se apresenta como uma concha oca, na qual o homem derrama, de vez em vez, matérias muito diferentes que se submetem à curva que as comprime e, assim, obtém uma significação inesperada. Logo, a rigidez obsessiva do mesmo sentido se apropria de experiências formais que ela não necessariamente provocou. Acontece que a forma se esgota completamente, ela sobrevive por um longo tempo à morte de seu conteúdo, mesmo que ela se renove de uma estranha riqueza (Focillon 1970: 6).

Alguns conceitos da linguística, em particular as teorias saussurianas, foram utilizados por Moret (1975: 293) como empréstimos comparativos para análise da linguagem iconográfica nas cenas presentes em um conjunto imagético. $\mathrm{O}$ primeiro deles se refere à diacronia e sincronia. $\mathrm{O}$ estudioso observou que o arqueólogo tem a sua disposição um material que se estende por muitos séculos e pode, portanto, englobar, em um só olhar, toda a história de um tema iconográfico e, assim, conhecer não apenas os antecedentes, mas também as transformações ulteriores das cenas que estuda.

A situação dos antigos, no entanto, era outra. O costume de enterrar os vasos junto com os mortos e mesmo o caráter friável das peças de uso cotidiano as colocava logo fora de circulação (ver Hoffman 1985/6: 64; 1988: 151-152). Nesse sentido, as gerações sucessivas de pintores e clientes puderam conhecer somente uma porção ínfima da imensa produção que as escavações recuperaram. Assim, segundo o Moret (1975: 293), não é adequado lhes emprestar uma visão que só o erudito de hoje pode ter graças ao distanciamento e à documentação da qual dispõe. Essa é uma observação importante, pois embora o arqueólogo trabalhe com um registro fragmentário do passado, este mesmo oferece, certamente, possibilidades analíticas interessantes.

A abordagem diacrônica que a Arqueologia utiliza é, portanto, consideravelmente relevante para evidenciar a criação e evolução do esquema, bem como do tema, no conjunto imagético. De início, é necessário pormenorizar a origem do motivo iconográfico e, em seguida, descrever sua aplicação temática. Tal análise permite esclarecer a relação entre o sentido original de um motivo e as diferentes aceitações que ele recebeu ao longo da evolução. Como lembrou Moret:

A significação de um motivo, em um determinado momento de sua evolução, não depende apenas de sua história, mas deve ser estabelecida a partir dos documentos contemporâneos. A dimensão histórica, por outro lado, permite compreender como as cenas se constituem em seu estado presente e como atuam sobre as demais. Muitas vezes, existe um arquétipo, uma representaçãomodelo, a partir da qual a influência se difundiu e que originou as demais dentro de sua órbita. Algumas são derivadas da primeira. Esse ponto de vista genealógico não tem sentido, entretanto, no plano horizontal ou sincrônico. Dizer que um motivo está esvaziado de sentido, ou que seu emprego é inapropriado em determinado contexto, só é concebível em uma perspectiva histórica; na ótica do pintor e de sua época, uma asserção desse tipo seria imprecisa ou mesmo errônea (Moret 1975: 294).

Nesse sentido, como lembra Shanks (1997: 102), é necessário conceber texto e imagem dialéticos como tangenciais ao passado - um vetor (do presente) que toca o passado no ponto do sentido e depois se move para explorar seu próprio curso, compartilhando da atualidade, a temporalidade da memória.

Outro conceito proveniente da linguística, emprestado por Moret (1975: 295), diz respeito 
às transformações analógicas. ${ }^{4} \mathrm{O}$ princípio da analogia é aquele que rege a maior parte das transformações iconográficas. Na própria imagem deve haver uma afinidade iconográfica que facilite a evolução analógica das duas cenas. Essa semelhança pode ocorrer no nível do mito, como um paralelismo de situação que permita a convergência das representações figuradas. Para o estudioso, o caso mais frequente é o da associação de idéias - temas -, algumas vezes, no entanto, a similitude formal - o esquema - é suficiente para justificar a passagem de um motivo de uma cena a outra.

Ocorre que a analogia é tanto um fator de transformação e renovação quanto pode desenvolver uma tendência à simplificação e à banalização, uma vez que opera em favor da regularidade e unificação dos procedimentos de formação e flexão. Nesse caso, ela "remodela, sobre um mesmo paradigma, cenas de origens diferentes" (Moret 1975: 296). Mas, muitas vezes, também pode empobrecer a linguagem iconográfica, mais que a enriquecer. À medida que seu emprego se torna mais frequente, $\mathrm{o}$ valor original do motivo se altera. De modo inverso, essa atenuação do sentido original permite que ele se adapte a cenas mais numerosas. Para o pesquisador:

As transformações funcionais podem ser explicadas tanto como inovações ou conservadorismo iconográficos: em um sintagma icônico (...) intervêm relações contextuais tão complexas que parece difícil distinguir entre elas as unidades pertinentes de variantes facultativas, as variantes facultativas se tornam traços pertinentes e vice-versa, de acordo com o código decidido pelo desenhista, os códigos frágeis fazem parte dos códigos icônicos (Moret 1975: 296).

(4) O estudioso lembrou que Panofsky ["zum Problem der Beschreibung und Inhaltsdeutung von Werken der bildenden Kunst" in Aufsätze zu Grundfragen der Kunstwissenchaft, 1964: 90-91] já havia demonstrado que a ação da analogia na imagética antiga foi mais marcante que a de qualquer fonte literária.
Assim, de acordo com Barthes, pode acontecer de uma cena lendária ser destituída de seu sentido original para tornar-se apenas um quadro vivo suscetível a receber o conteúdo de um outro mito. Aquilo que ele chamou "permutação paradoxal das operações de leitura, a regressão anormal do sentido à forma" (Barthes 1970: 203).

Todavia, Moret (1975: 296) observou que, "de forma geral, é mais fácil constatar o resultado da ação analógica que determinar os mecanismos dessa ação isolando um fenômeno preciso da mutação”. A partir da intenção estilística inerente à arte, o pesquisador considerou ser difícil conceber que os pintores da Antiguidade não fossem sensíveis aos imperativos decorativos, pois, segundo ele, é possível demonstrar, em exemplos precisos, que são justamente as pesquisas ornamentais que conduziram às transformações iconográficas. Embora seja exemplo de inovações individualizadas, a cerâmica antiga, justamente por ser produzida em série, esteve exposta, mais que qualquer outro gênero artístico, aos fenômenos de contaminação.

Em relação ao conceito de sinonímia e homonímia, também emprestado da linguística, Moret (1975: 296-297) observou que o único termo de referência que pode ser contraposto à imagem não é a palavra e nem a frase, mas o texto inteiro. Assim, se quisermos seguir a comparação entre linguagem iconográfica e linguagem comum (sic), existe uma dificuldade que advém do fato de os sinônimos na linguagem existirem no nível das palavras ou, no máximo, das frases. Não é possível dizer que dois textos são sinônimos, mas podem-se imaginar dois textos que exprimem a mesma idéia ou que contam a mesma história com frases e palavras diferentes.

No caso da iconografia, o estudioso define os sinônimos como: "as representações de um mesmo episódio lendário em esquemas gráficos diferentes" (Moret 1975: 297). Contudo, lembra que é preciso atentar para o fato de que toda modificação formal - em nível da composição - quase que necessariamente causa uma modificação no sentido da imagem. Assim, no 
jogo de ações e reações exercidas pelo mito sobre a imagem, e da imagem sobre o mito, ocorre a metamorfose de duas entidades. É por isso que o estudioso afirma que na iconografia só se pode falar de sinonímia em sentido figurado, situando essa identidade de significação para além da cena representada. A escolha dos temas responde a um plano premeditado e as cenas lendárias, em vez do valor em si mesmas, convergem em direção a uma mesma idéia, na qual o sentido se manifestará apenas na unidade do programa ao qual ela será subordinada.

Em relação ao fenômeno da homonímia, Moret (1975: 298) o descreveu como "as imagens de aspecto idêntico, ou quase idêntico, às quais são atribuídos sentidos distintos". $\mathrm{O}$ equivalente linguístico seria o da poesia ou dos esquemas métricos fixos, sobrepostos aos códigos comuns e suscetiveis a receber conteúdos semânticos diferentes. Na expressão escrita, a precisão não é a mesma, os sentidos se cristalizam com a ajuda de elementos ou de signos secundários. Na iconografia esses traços precisos também existem: são os elementos decorativos, os atributos ou elementos secundários que permitem estabelecer a situação lendária em questão.

Assim, pode-se falar de determinação contextual. Do mesmo modo que na linguagem o sentido de uma palavra depende do contexto em que aparece, na iconografia, um motivo pode mudar de acepção de acordo com a cena em que é empregado. $O$ contexto deve indicar com clareza sem que reste qualquer dúvida. A cena deve ser lida em sua totalidade para poder precisar o valor do motivo e determinar aquele, entre os sentidos, que convém à ocorrência. Do contrário, a ausência de todo traço pertinente conduzirá a uma ambiguidade irredutível.

No momento em que o pintor esboça a cena, lembrou Moret, ele também se refere ao mito específico, do qual tem um conhecimento mais ou menos preciso. A menos que ele copie uma outra representação figurada, ainda assim, trata-se de uma transcrição por referência: "as inovações ocorrem, quase sempre, nos detalhes, mesmo no caso de uma situação inteiramente nova e, até então, desconhecida, não podemos provar que o pintor não se inspirou em uma tradição literária que não chegou até nós" (Moret 1975: 301). Como vimos, uma origem nas fontes textuais é apenas uma das diferentes possibilidades existentes para a gênese de uma representação, prová-la ou não nem sempre está ao alcance do pesquisador.

Autônoma, a tradição figurativa evoluiu independentemente da tradição literária. Essa liberdade não causou, imediatamente, a desintegração dos tipos nem a ruína da imagética lendária, mas, nesse processo de fusão e padronização, as cenas foram banalizadas. $\mathrm{O}$ repertório de temas representados torna-se sempre mais restrito em meios novos de expressão. Aí reside a razão do emprego de esquemas iguais para temas diferentes. Assim, segundo Moret, o fenômeno de sobrevivência da forma apesar da morte do conteúdo original, descrito por Focillon, era impossível de acontecer no período de formação da mitologia figurativa:

Forma e conteúdo ainda não eram elementos independentes, associados ocasionalmente, mas componentes indissociáveis de uma mesma e única realidade: a representação. Inseparáveis, os dois termos eram função um do outro, a significação do episódio era amplamente condicionada pela maneira como era representado e, inversamente, o meio de expressão era ditado por seu tema. (...) A variação dupla só é viável em um estado avançado de evolução, em que os dois termos em jogo, tipo formal de um lado, situação lendária de outro, adquiriram uma rigidez suficiente (Moret 1975, p. 305).

A abordagem de Lissarrague e Schnapp (1981: 285), por sua vez, seguiu outra direção. Para os autores, a imagem não pode ser lida como uma mera ilustração - de um texto, de um ritual ou de um evento político -, mas como um conjunto de signos com sua lógica própria. Por isso, lhes interessam as fórmulas, as repetições, mais que os detalhes, ou as singularidades. Assim, o lugar da imagem no vaso e sua relação com as demais cenas figura- 
das no mesmo vaso, remetem a uma significação tão importante quanto a evolução ou a difusão da própria imagem.

Essas questões remetem aos conceitos de intertextualidade e, por conseguinte, de intericonicidade. A intertextualidade, termo cunhado por Kristeva (1967: 438-465), foi utilizada pela linguística para designar a influência ou a utilização de um texto, ou de uma multiplicidade de textos, ou excertos de textos preexistentes, que são utilizados como modelo ou ponto de partida e cuja interação resulta na elaboração de um novo texto literário. A intericonicidade, por extensão de significado, remete aos processos de produção de uma imagem, a partir da reutilização de outra imagem preexistente, ou dos elementos formais de uma imagem na elaboração de uma nova imagem. Assim, uma imagem, ou imagens, é transportada para outro contexto imagético diferente daquele original e tais representações podem até, nos casos mais extremos, adquirir uma outra significação. A intericonicidade está, portanto, associada não apenas ao contexto de produção artística, no qual se deu sua aplicação, mas também remete a todos os aspectos da dinâmica social, política e ideológica do período em que se desenvolve.

Nesse sentido, o conceito de intericonicidade refere-se à assimilação de diferentes padrões iconográficos, de origem autóctone ou estrangeira, anterior ou contemporânea, em uma determinada representação ou conjunto imagético, capaz de criar diálogos distintos dos originais e favorecer o desenvolvimento de novos esquemas iconográficos. ${ }^{5}$

\section{Visibilidade e proporcionalidade imagética: a análise proxêmica}

Algumas teorias da percepção aplicadas à imagem consideram-na um processo de varredura visual que envolve atenção seletiva sobre elementos informativos específicos. Assim, quanto mais visível está um elemento em uma

(5) Para uma aplicação dessas teorias, ver Aldrovandi 2006. representação em relação aos demais, maior a probabilidade de ele ser encontrado e observado pelo espectador. A distribuição e visibilidade relativa dos elementos materiais dessa informação representada podem, portanto, ter uma relação demonstrável com a sua significância comunicativa (cf. Molyneaux 1997b: 112).

Acontece, como observou Molyneaux (1997b: 103, 114-115), que a representação da informação em si é sensível ao estímulo ideológico durante a situação da produção. Assim, as forças ideológicas atuantes em uma sociedade afetam a posição que o artista toma em relação a temas específicos e, portanto, influenciam a organização da significação social nas representações. As representações ampliam e reforçam mensagens existentes que aparecem em outras formas. A análise da paisagem social, apresentada pelo autor, decorre do estudo da interação social e das relações de status presentes nas representações visuais, por meio das quais o artista consegue comunicar o status individual das figuras utilizando a forma. Isto é, o esquema formal é utilizado como um instrumento de estímulo na paisagem metafórica da imagem, como meio de chamar a atenção para seus aspectos significantes.

O artifício compositivo mais direto a informar o status e poder da realeza é a visibilidade, pois esta é representada em escala monumental para chamar, num primeiro momento, a atenção do espectador. Mas o artista recorre a estratégias mais sutis que a escala, para dirigir o olhar do espectador a outros elementos compositivos: o movimento (Molyneaux 1997b: 116-117).

Assim, as diferenças nas relações ideológicas presentes no âmbito social são sinalizadas pelas distinções na visibilidade dos respectivos indivíduos ou elementos no campo da arte. Uma análise dos fatores informacionais, externos ao significado, favorecem a verificação dos ajustes visuais presentes em diferentes situações ideológicas, num longo período de tempo.

Segundo Molyneaux (1997b: 122-123), é possivel analisar e interpretar a visibilidade relativa das figuras de uma maneira neutra e objetiva, 
simplesmente ao medir e comparar os vários atributos proxêmicos, ou seja, as representações espaciais das relações sociais das figuras - como altura, distância entre uma figura e outra, postura e posição dentro das cenas. A análise proxêmica é o estudo das distâncias físicas que as pessoas estabelecem espontaneamente entre si no convívio social e das variações dessas distâncias de acordo com as condições ambientais e os diversos grupos ou situações sociais e culturais em que se encontram, aqui aplicada às representações imagéticas.

A premissa básica dessa análise é que o artista representa a significação de várias pessoas e objetos em uma imagem, por meio do aumento da sua visibilidade de algum modo material, a fim de dirigir a atenção do espectador. Assim, é possível ter uma idéia da mudança de significação ideológica por meio da visibilidade literalmente medindo e comparando a quantidade de informação devotada aos indivíduos de status diferentes em uma determinada cena (Molyneaux 1997b: 125-126). Nos casos em que a cronologia dos conjuntos imagéticos é mais precisa, esse tipo de análise torna ainda mais clara as variações nas relações sociais impressas nas imagens, pois é possível observar as mudanças ocorridas ao longo dos períodos históricos.

\section{Considerações finais}

As abordagens teóricas apresentadas ao longo deste artigo fornecem uma ampla gama de instrumentos para a análise e interpretação dos repertórios imagéticos das mais diferentes sociedades antigas. Apesar de formulados, em sua quase totalidade, a partir de estudos realizados sobre conjuntos iconográficos de origem grega ou mediterrânea, estes fundamentos teóricos podem ser aplicados a qualquer repertório destas ou de outras civilizações do passado. A análise imagética possibilita a compreensão de aspectos intrínsecos ao modo como essas sociedades se auto-representavam. Isto porque, apesar das diferenças e idiossincrasias que cada sociedade pretérita possuiu, as imagens legadas por estas mesmas obedecem a uma linguagem cujos discursos, se devidamente fundamentados, podem certamente ser evidenciados e decifrados.

\section{Agradecimentos}

Ao labeca pelo apoio constante. À FAPESP pelo financiamento da pesquisa.

ALDROVANDI, C.E.V. Past imagery: theoretical perspectives on the Archaeology of Image. Revista do Museu de Arqueologia e Etnologia, São Paulo, 19: 39-61, 2009.

Abstract: Some theoretical perspectives developed by the Archaeology of Image are presented and discussed in this article, providing a valuable basis for analyzing and interpreting past iconographic repertoires.

Keywords: Archaeology - Image - Iconography - Semantics - Intericonicity.

\section{Referências bibliográficas}

BANDINELLI, R.B.

1961 Archeologia e Cultura. Milano-Napoli. BARTHES, R.

1970 Mythologies. Paris: Éditions du Seuil.
BÉRARD, C.

1974 Anodoi - Essai sur l'Imagerie des Passages Chthoniens. Institute Suisse de Rome, Bibliotheca Elvetica 
Romana, XIII. Switzerland: Paul Attinger S.A.

1985 Modes de formation et modes de lecture des images divines: Aphrodite et Isis à la voile. In Giraud, E. (Ed.) Eidolopoiia, Actes $d u$ Colloque sur les problémes de l'image dans le monde méditerranén classique, 1982 Château de Lourmarin en Provence. Rome, Giorgio Bretschneider Ed.:163-71.

BÉRARD, C.; DURAND, J.-L.

1984 Entrer en imagerie. In Nathan, F. (Ed.) La Cité des Images: Religion et Société en Gréce Antique. Lausanne, Editions de la Tour: 20-34.

CHAMPION, T.

1997 The Power of the Picture: the Image of the Ancient Gaul. In Molineaux, B.L. (Ed.) The Cultural Life of Images - cultural representation in archaeology. London, Routledge: 213-229.

CLERMONT-GANNEAU, C.

1878 Mythologie iconologique chez lês Grecs. Revue Critique, 215-223 et 232-230.

1880 L'Imagerie phénicienne et la Mythologie iconologique chez les Grecs. Paris: Ernest Leroux.

BRUNEAU, PH.

1986 De L'Image. Ramage, 4: 249-95.

DUGAS, C.

1936 Décoration et imagerie dans la céramique grecque. Revue des Études Grecques, 49: 440-64 [reeditado em Recueil C. Dugas, Paris: Éditions E. de Boccard, 1960].

1937 Tradition litéraire et tradition graphique dans l'antiquité grecque. L'Antiquité Classique, 6: 5-26.

FOCILLON, H.

1939 La Vie des Formes. L'éloge de la main. Paris: Denöel.

GOMBRICH, E. H.

1960 Art and Illusion: a study in the psychology of pictorial representation. Bollingen Series XXXV: 5. Princeton University Press.

1972 Symbolic Images: Princeton University Press.

HOFFMANN, $\mathrm{H}$.

1985/6 Iconography and Iconology. Hephaistos, 7/8: 61-6.

1988 Why did Greeks need Imagery? An anthroplogical approach to the study of Greek vase painting. Hephaistos, 9: 143-162.

KRISTEVA, J.

1967 Bakhtine, le mot, le dialogue et les roman. Critique, XXIII, 239: 438-65.
LISSARRAGUE, F.; SCHNAPP, A.

1981 Imagerie des Grecs ou Grèce des Imagiers? Le Temps de la Reflexion. Paris, Gallimard, v. 2: 275-97.

MENESES, U.B.

1967 Imagem Conceitual e Representação: observações sobre o mundo da imagem visual na Grécia antiga. Dédalo - Revista de Arte e Arqueologia, Ano III, 5: 26-39, São Paulo: Museu de Arte e Arqueologia, USP.

METZGER, $\mathrm{H}$.

1985 Sur le valeur de l'attribut dans l'interprétation de certaines figures du monde éleusinien. In Giraud, E. (Ed.) Eidolopoiia, Actes du Colloque sur les problémes de l'image dans le monde méditerranén classique, 1982 - Château de Lourmarin en Provence. Rome: Giorgio Bretschneider Ed.: 173-9.

MOLYNEAUX, B.L. (Ed.)

1997a The Cultural Life of Images: cultural representation in archaeology. London: Routledge.

1997b Representations and reality in private tombs of the late eighteenth dynasty, Egypt. In Molyneaux, B.L. (Ed.) The Cultural Life of Images - cultural representation in archaeology. London, Routledge: 108-29.

MORET, J.-M.

1975 L'Ilioupersis dans la Céramique Italiote - Les Mythes et leur Expression Figurée au IVe Siècle. Tome I, Institute Suisse de Rome, Switzerland, Univ. de Genève.

PANOFSKY, E.

1939 Studies in Iconology. New York: Harper Torchbook.

1955 Significado nas Artes Visuais. São Paulo: Editora Perspectiva.

SARIAN, H.

1987 A expressão imagética do mito e da religião nos vasos gregos e de tradição grega. Cultura Clássica em Debate, 6, Anais do I Congresso Nacional de Estudos Clássicos, UFMG: 15-48.

SARTRE, J.P.

1987 A Imaginação. Coleção Os Pensadores. São Paulo: Editora Nova Cultural.

SHANKS, M.

1997 Photography and Archaeology. In Molyneaux, B.L. (Ed.) The Cultural Life of Images - cultural representation in archaeology. London, Routledge: 73- 107.

SHAPIRO, H.A.

1994 Myth into Art, Poet and Painter in Classical Greece. London: Routledge. 


\section{SNODGRASS, A.M.}

1982 Narration and Allusion in Archaic Greek Art. J.L. Myres Memorial Lectures. London: Leopard's Head Press.

1987 La naissance du récit dans l'art grec. In Bérard, C.; Bron, Ch.; Panari, A. (Eds.) Images et Société en Grèce Ancienne, L'Iconografie comme Méthode d'Analyse, Actes $d u$ Colloque International, Lausanne 1984. Institut d'Archéologie et d'Histoire Ancienne, Université de Lausanne, Lausanne: 11-18.

SPARKES, B.A

1997 Some Greek images of others. In
Molyneaux, B.L. (Ed.) The Cultural Life of Images - cultural representation in archaeology. London, Routledge: 130-55.

STEINER, D.T.

2001 Images in Mind, Statues in Archaic and Classical Greek Literature and Thought. Princeton: Princeton University Press.

VERNANT, J.P.

1984 Preface. In Nathan, . (Ed.) La Cité des Images: Religion et Société en Grèce Antique. Lausanne, Editions de la Tour: 4-5.

1990 Figures, idoles, masques. Paris: Julliard.

Recebido para publicação em 25 de maio de 2009. 